\title{
Cowden syndrome. Managing multiple skeletal metastases of different origin: a case report
}

\author{
Antonios Angoules1, Evangelia Maria Tsapakis ${ }^{2}$, Ioannis Polyzois ${ }^{1}$, \\ Zakareya Gamie ${ }^{1}$, James Julian Rankine ${ }^{1}$ and Eleftherios Tsiridis*1
}

\author{
Address: ${ }^{1}$ Academic Orthopaedic Unit, Leeds General Infirmary, Leeds School of Medicine, Leeds, LS1 3EX, UK and ${ }^{2}$ Institute of Psychiatry, King's \\ College London, London, UK \\ Email: Antonios Angoules - antangules@med.uoa.gr; Evangelia Maria Tsapakis - Eva-Maria.Tsapakis@iop.kcl.ac.uk; \\ Ioannis Polyzois - polyzois@hotmail.co.uk; Zakareya Gamie - ugm1zg@gmail.com; James Julian Rankine - james.rankine@leedsth.nhs.uk; \\ Eleftherios Tsiridis* - etsiridis@doctors.org.uk \\ * Corresponding author
}

Published: 23 October 2008

Cases Journal 2008, 1:265 doi:10.1 186/1757-1626-1-265

This article is available from: http://www.casesjournal.com/content/I/I/265

(c) 2008 Angoules et al; licensee BioMed Central Ltd.

This is an Open Access article distributed under the terms of the Creative Commons Attribution License (http://creativecommons.org/licenses/by/2.0), which permits unrestricted use, distribution, and reproduction in any medium, provided the original work is properly cited.
Received: 16 October 2008

Accepted: 23 October 2008

\begin{abstract}
Background: Cowden Syndrome is a rare autosomal dominant multiple hamartomatous condition, characterised by both benign and malignant tumours affecting multiple systems.

Case presentation: We present a 47-year-old female patient with thigh pain that was diagnosed with Cowden syndrome 20 years ago and developed multiple and different skeletal metastases which became resistant to radio-chemotherapy. A percutaneous plate fixation of the distal femur with an intralesional excision and cementoplasty of the metastasis was performed initially. This was combined with a cemented total hip arthroplasty using an Exeter long revision stem and a cementoplasty of the femoral canal for the proximal lesions.
\end{abstract}

Conclusion: A meticulous approach to her complex metastatic disease resulted in successful palliative prophylactic reconstructive surgery that improved her quality of life, allowing her independent pain free walking for 12 months.

\section{Background}

Cowden Syndrome (CS) is a rare autosomal dominant disorder characterised by multiple hamartomas and an increased risk of breast, thyroid and endometrial carcinomas [1,2] Germline mutations in the tumour suppressor gene PTEN (phosphatase and tensin homolog) chromosome 10q23.2, which codes for a lipid phosphate mediating cell cycle arrest and apoptosis, were first described in Cowden Syndrome[3] In the next years since PTEN had been identified as the major CS susceptibility gene[4], a number of inherited cancer and developmental syndromes were associated with germline PTEN mutations. It has therefore been proposed that all such syndromes based on molecular defects are classified as PTEN Hamartoma Tumour Syndromes (PHTS)[2,5]. Irrespective of clinical phenotype however, the discovery of a germline PTEN mutation should trigger cancer risk surveillance[6]. Skeletal metastases of multiple origins are difficult to treat and palliative surgery usually requires a combination of approaches and techniques.

\section{Case presentation}

A 47-year-old female Caucasian patient presented with a right sided limp and ipsilateral thigh pain with an established diagnosis of CS according to the International Cowden Syndrome Consortium Operational Criteria1, 
positive for tumour suppressor phosphatase and tensin homolog gene (PTEN) mutation.

She was first diagnosed with thyroid follicular carcinoma and was treated with a thyroidectomy in 1989. The patient then developed breast cancer in 1991 for which she underwent lumpectomy followed by adjuvant radiochemotherapy. Due to local recurrence the following year, she was treated with a left mastectomy and a few months later she underwent right nephrectomy for renal carcinoma. In 2003, she was diagnosed with left scapular renal metastatic and during the same year she developed brain metastases that required a right frontal lobe resection followed by whole brain radiotherapy. On presentation, she was known to have pulmonary and multiple bone metastases. Palliative skeletal radiotherapy was completed having exceeded the maximum radiation limits. As a last resort, she was on interferon treatment as well as bisphosphonates for palliation therapy.

On clinical examination, the right hip was painful with a restricted range of motion and she was unable to weight bear. At the distal part of her right femur a pulsatile mass could be felt but the knee had normal function with no effusion. There was no neurovascular deficit detectable. She scored 8 out of 10 in the visual analogue scale VAS for pain (VAS-P) and 3 out of 10 in the quality of life EuroQolVAS (VAS-EQ) questionnaires[7]. The Harris Hip Score[8] (HHS) was 46, the Beck Depression Index[9] (BDI) 28, the State-Trait Anxiety Index[10] (STAI) was 69, and she was given a score of 3 according to the American Society of Anesthesiologists (ASA)[11]. Radiographs of the pelvis and the entire right femur showed a destructive osteolytic lesion of the femoral head and neck occupying more than $50 \%$ of the bony mass with thinning of the medial femoral neck cortex and a large osteolytic lesion in the ipsilateral supracondylar region. Magnetic resonance imaging (MRI) of the right femur revealed a $5.3 \mathrm{~cm}$ in diameter bone metastasis within the distal femur which was breaching the posterior cortex and encroaching on the popliteal vessels (Figure 1, Figure 2 Figure 3). A vascular metastatic extrusion in the suprapatellar pouch was also detected (Figure 3). In addition, there was a similar lesion at the level of the lesser trochanter with an ill-defined intra-medullary component and marked cortical reaction (Figure 1). A $2.4 \mathrm{~cm}$ mass within the right femoral head extending into the subchondral bone and a second $3.5 \mathrm{~cm}$ mass in the femoral neck of lower intensity in STIR coronal views were also detected (Figure 2). MRI of the pelvis revealed vascular metastatic lesions adjacent to the acetabular roof and the posterolateral wall. The rest of the ipsilateral ilium and ischium were intact. Laboratory tests including a full blood count, renal, liver, thyroid function tests, clotting profile and parathyroid hormone levels were all within normal limits.

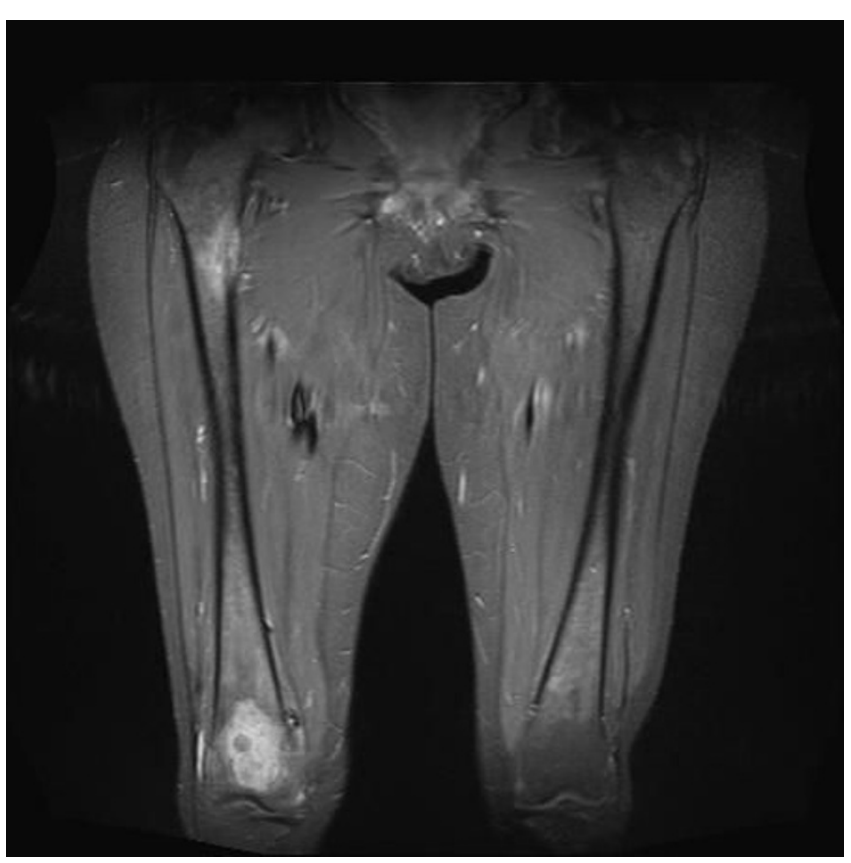

Figure I

TI weighted fat suppressed post gadolinium coronal views of the whole right femur. Vascular lesions are shown at the distal intercondylar femoral site and the proximal femur adjacent to the lesser trochanter.

\section{Surgical planning and technique}

The two destructive osteolytic lesions of the right femur scored more than 9, according to Mirels classification [12]. An imminent pathological fracture in the proximal and distal femur was thus diagnosed and a multi-disciplinary team meeting took place to discuss the management of this case. The question of long-term survival was raised but no definitive answer was given as the patient had survived this multiple neoplasia syndrome for over 20 years. The dilemma of palliative prophylactic surgery was also debated. The option of femoral nailing (ante- or retrograde) was ruled out due to lack of proximal bony support (femoral neck and acetabular metastasis) and the presence of a distal vascular lesion (exophytic metastasis with vascular MRI signal in the distal femur bridging both the anterior and the posterior distal femoral cortices). Total femoral replacement with a hinged constrained total knee arthroplasty could provide a solution but meticulous anatomical dissection close to the popliteal vessels would be necessary and potentially hazardous. Above knee amputation was an option. However, healing of the stump and loading of the limb would not improve her mobility and quality of life since the metastatic disease was also affecting the ipsilateral hip joint. The distal femur (Mirels classification score 11) was considered to have priority as an imminent fracture was at greater risk compared to the proximal femur (Mirels classification score 9). The patient 


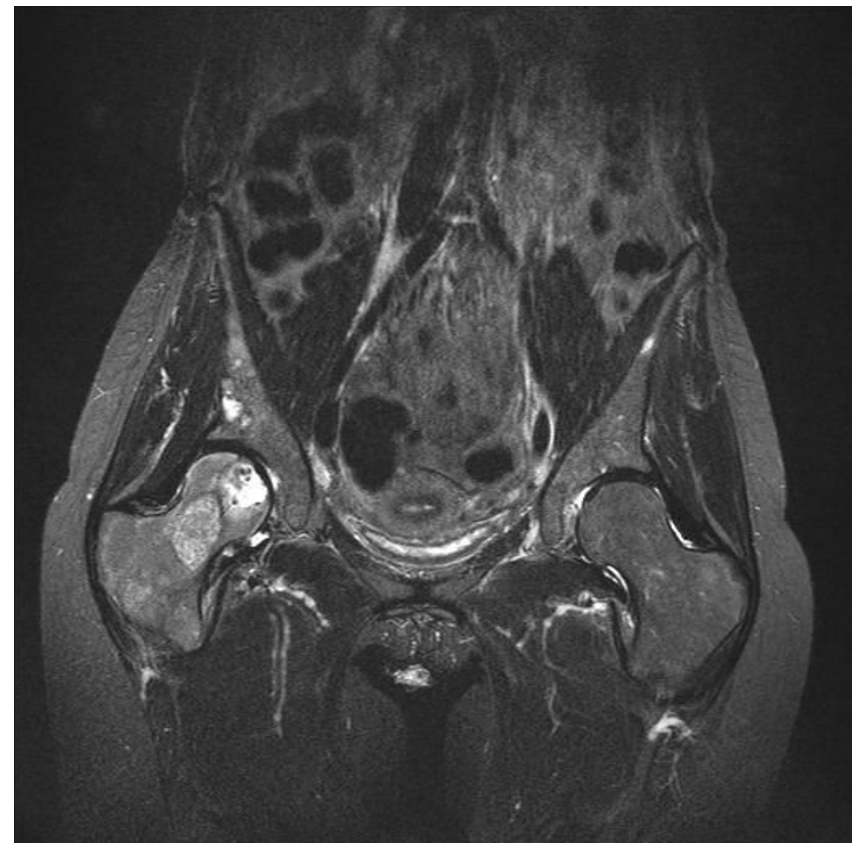

Figure 2

Coronal T2 weighted fat suppressed (STIR) view of the right hip joint. Two different signals in the femoral neck. The most proximal was similar to subtrochanteric and distal femoral intercondylar signal most possibly of vascular origin. The most distal lesion was less vascular.

discontinued interferon therapy for two weeks before surgery. Successful embolisation of the vascular lesions in the acetabulum, proximal and distal femur was performed twenty-four hours prior to surgery. On the operating table the patient was placed in the lateral decubitus position to allow access to both the distal femur and hip joint. A lateral approach to the distal femur was first performed at the level of the lesion and was extended to the femoral condyles in order to allow positioning of a locking plate at that level. The tumour was then approached from the anterior femoral cortex above the patella and resected. Following this, the locking plate was applied percutaneously and was measured in length to overlap proximally the distal end of the cemented femoral prosthesis which was implanted at a second stage. The distal femur was then augmented by methylmethacrylate cement injection to fill the void. No major bleeding was encountered and the cement injection was controlled with continuous radiographic imaging to prevent leakage into the popliteal fossa. Subsequently, the hip joint was opened via a posterior approach. A standard procedure with short rotators and capsular tagging for repair was performed and a cemented Exeter total hip arthroplasty using a long stem (200 $\mathrm{mm})$ was inserted. Meticulous curettage of the metastatic lesions from the acetabular and femoral medullary site was also performed in order to debulk the metastatic

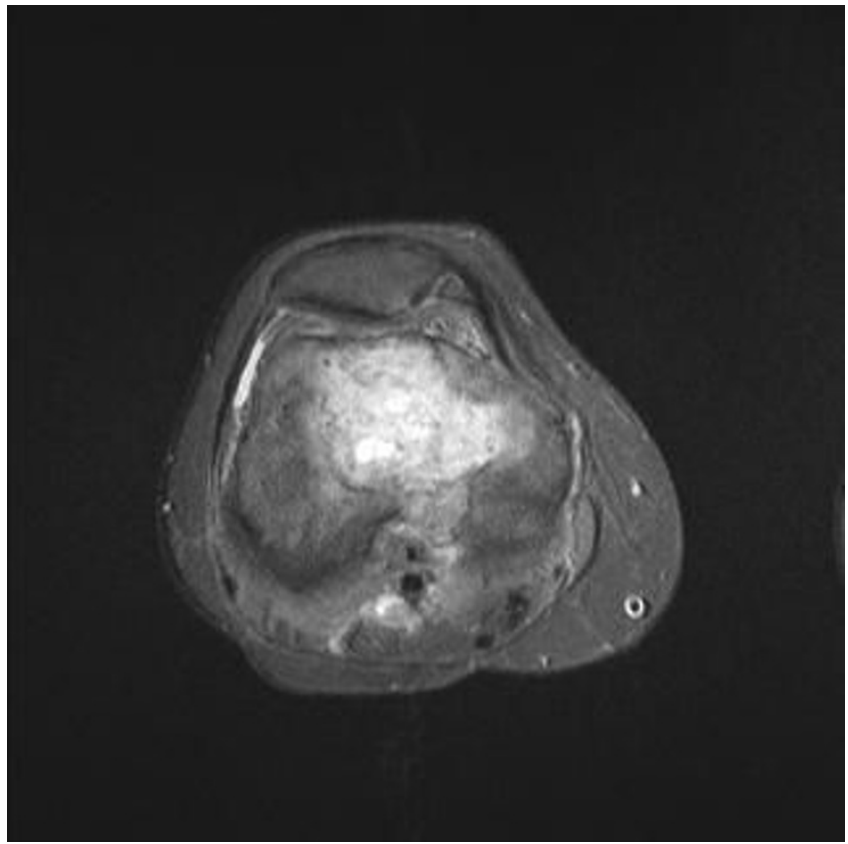

Figure 3

TI fat suppression post gadolinium axial view of the distal femur. The metastasis is bridging the anterior and the posterior femoral cortex and in places is in very close proximity to the popliteal neurovascular structures.

mass and replace it with cement. There was no cement restrictor placed and the cement was pressurised to fill the femoral canal as far distally as possible. Venting of the femoral canal was performed through predrilled $4.5 \mathrm{~mm}$ holes in the lateral cortex (Figure $4 a, 4 b, 4 c$ ). The patient made an uneventful recovery and started fully weight bearing within a week from surgery. The blood loss (total estimated $700 \mathrm{mls}$ ) was within expectations and blood transfusion was not necessary. Within the first 6 weeks the HHS improved to 90 , the BDI to 12 , the STAI to 48 , the VAS-P to 3 and the VAS-EQ to 9. The post operative histopathological examination of the specimens retrieved from the distal femur revealed metastatic renal cell carcinoma. The femoral head and acetabular lesions were also of renal origin whilst the femoral neck lesion was a breast tumour metastasis. The patient continued interferon and bisphosphonate treatment thereafter, and survived for a year having a good quality of life and full mobility.

\section{Discussion}

Our patient presented with a long history of metastatic CS resistant to radio-chemotherapy. We elected to proceed to a combined surgical treatment of both the proximal and distal femoral metastases leaving the unaffected mid femur intact. A percutaneous plate fixation of the distal femur with an intralesional excision and cementoplasty of the metastasis was performed initially. This was combined 

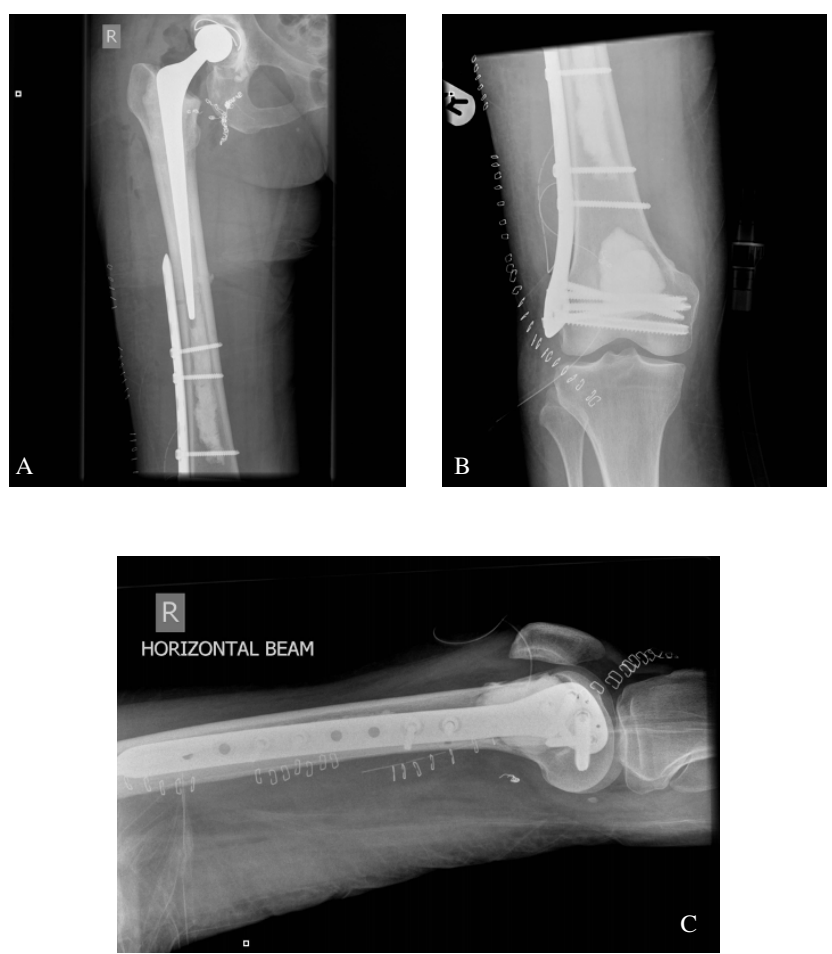

Figure 4

(a) Anteroposterior view of the proximal femur. A long cemented Exeter total hip arthroplasty. There is no cement restrictor and the cement has been pressurized to the distal femoral canal. (b\&c) Anteroposterior and lateral view of the distal femur. Cementoplasty and locking percutaneous plating of the distal femur.

with a cemented total hip arthroplasty using an Exeter long revision stem and a cementoplasty of the femoral canal. Weber et al[13] recommended curettage with cementation and stabilization for metastatic renal cell carcinomas that are refractory to local adjuvants such as radiotherapy. They showed that this can decrease local progression of the disease. The same authors also advised embolization twelve to thirty six hours pre-operatively for renal cell and thyroid carcinomas especially if the procedure is performed without a tourniquet as in our case. Recently Fuchs et al[14] reported no difference in the long-term survival between wide resection and intralessional curettage of renal cell metastases. However the functional morbidity of a widespread resection and reconstruction and its effect on weight-bearing should be considered and weighed against the potential prolongation of survival. Cemented THA with long stem femoral implant and cemented acetabular component are also recommended for metastatic long bone disease. Uncemented implants are contraindicated as the bone is biologically inert following previous or adjuvant radiotherapy and does not therefore allow ingrowth onto the implants[13].
Cardiopulmonary compromise and thromboembolic events can be minimised by venting the femoral canal and lowering cement pressurisation [15].

In our case, preoperative biopsy or intraoperative frozen section biopsy were deemed unnecessary as the MRI features of the metastatic lesions were vascular and therefore of renal or thyroid origin.

Mirels classification system is a reliable method of predicting the likelihood of a pathological fracture and was used along with the clinical evaluation of the overall functional status of the patient to guide our treatment[16]. We believe that by preserving the femur we have maintained the limb's functional capacity to a significant extent. That would possibly not have been the case if a widespread bone resection or a complex replacement reconstructive procedure had taken place[17]. In addition to, our surgical approach allowed bone cementoplasty enhancement avoiding major resections, excessive blood loss and a high risk of postoperative infection.

\section{Conclusion}

This case reports on CS, a rare disease with multiple skeletal metastases of different origin. The treatment included a combination of cemented arthroplasty, cementoplasty and internal fixation that maintained function and improved our patient's quality of life.

\section{Consent}

Written informed consent was obtained from the patient's husband for publication of this case report and accompanying images in Journal of Medical Case Reports.

\section{Competing interests}

The authors declare that they have no competing interests.

\section{Authors' contributions}

AA collected the clinical details, analysed and interpreted radiographs as well as drafted the first manuscript. EMT prepared the first draft of the manuscript and contributed to the patient's management. IP conducted a literature search and contributed to preparation of the final manuscript. ZG conducted a literature search and contributed to preparation of the final manuscript. JJR contributed to the interpretation of the radiographs and preparation of the manuscript. ET carried out the surgery and helped with preparation of the final manuscript. All authors contributed equally in collecting patient data and editing radiographic images.

\section{References}

I. Eng C: Will the real Cowden syndrome please stand up: revised diagnostic criteria. J Med Genet 2000, 37:828-30.

2. Eng C: PTEN: one gene, many syndromes. Hum Mutat 2003, 22: $183-98$. 
3. Liaw D, Marsh DJ, Li J, Dahia PL, Wang SI, Zheng Z, Bose S, Call KM, Tsou HC, Peacocke M, Eng C, Parsons R: Germline mutations of the PTEN gene in Cowden disease, an inherited breast and thyroid cancer syndrome. Nat Genet 1997, 16:64-7.

4. Marsh DJ, Kum JB, Lunetta KL, Bennett MJ, Gorlin RJ, Ahmed SF, Bodurtha J, Crowe C, Curtis MA, Dasouki M, Dunn T, Feit H, Geraghty MT, Graham JM Jr, Hodgson SV, Hunter A, Korf BR, Manchester D, Miesfeldt S, Murday VA, Nathanson KL, Parisi M, Pober B, Romano C, Eng $C$, et al.: PTEN mutation spectrum and genotype-phenotype correlations in Bannayan-Riley-Ruvalcaba syndrome suggest a single entity with Cowden syndrome. Hum Mol Genet 1999, 8:146I-72.

5. Nelen MR, van Staveren WC, Peeters EA, Hassel MB, Gorlin RJ, Hamm H, Lindboe CF, Fryns JP, Sijmons RH, Woods DG, Mariman EC, Padberg GW, Kremer H: Germline mutations in the PTEN/ MMACI gene in patients with Cowden disease. Hum Mol Genet 1997, 6: I383-7.

6. Nelen MR, Padberg GW, Peeters EA, Lin AY, Helm B van den, Frants RR, Coulon V, Goldstein AM, van Reen MM, Easton DF, Eeles RA, Hodgsen S, Mulvihill J], Murday VA, Tucker MA, Mariman EC, Starink TM, Ponder BA, Ropers HH, Kremer H, Longy M, Eng C: Localization of the gene for Cowden disease to chromosome 10q2223. Nat Genet 1996, 13:114-6.

7. van Agt HM, Essink-Bot ML, Krabbe PF, Bonsel GJ: Test-retest reliability of health state valuations collected with the EuroQol questionnaire. Soc Sci Med 1994, 39: I537-44.

8. Harris $\mathrm{WH}$ : Traumatic arthritis of the hip after dislocation and acetabular fractures: treatment by mold arthroplasty. An end-result study using a new method of result evaluation. J Bone Joint Surg Am 1969, 5 1:737-55.

9. Beck AT, Steer RA: Internal consistencies of the original and revised Beck Depression Inventory. J Clin Psychol 1984 40:1365-7.

10. Kvaal K, Ulstein I, Nordhus IH, Engedal K: The Spielberger StateTrait Anxiety Inventory (STAI): the state scale in detecting mental disorders in geriatric patients. Int $J$ Geriatr Psychiatry 2005, 20:629-34.

II. Saklad M: Grading of patients for surgical procedures. Anaesthesiology 1941:28|-4.

12. Mirels H: Metastatic disease in long bones. A proposed scoring system for diagnosing impending pathologic fractures. Clin Orthop Relat Res 1989:256-64.

13. Weber KL, Randall RL, Grossman S, Parvizi J: Management of lower-extremity bone metastasis. J Bone Joint Surg Am 2006, 88(Suppl 4): I I-9.

14. Fuchs B, Trousdale RT, Rock MG: Solitary bony metastasis from renal cell carcinoma: significance of surgical treatment. Clin Orthop Relat Res 2005:187-92.

15. Randall RL, Aoki SK, Olson PR, Bott SI: Complications of cemented long-stem hip arthroplasties in metastatic bone disease. Clin Orthop Relat Res 2006, 443:287-95.

16. Damron TA, Morgan H, Prakash D, Grant W, Aronowitz J, Heiner J: Critical evaluation of Mirels' rating system for impending pathologic fractures. Clin Orthop Relat Res 2003:S20I-7.

17. Lin PP, Mirza AN, Lewis VO, Cannon CP, Tu SM, Tannir NM, Yasko AW: Patient survival after surgery for osseous metastases from renal cell carcinoma. J Bone Joint Surg Am 2007, 89: $1794-80 \mid$.
Publish with Biomed Central and every scientist can read your work free of charge

"BioMed Central will be the most significant development for disseminating the results of biomedical research in our lifetime. "

Sir Paul Nurse, Cancer Research UK

Your research papers will be:

- available free of charge to the entire biomedical community

- peer reviewed and published immediately upon acceptance

- cited in PubMed and archived on PubMed Central

- yours - you keep the copyright
BioMedcentral 